\title{
An Interpersonal Circumplex Model of Children's Social Goals: Links With Peer-Reported Behavior and Sociometric Status
}

\author{
Tiina Ojanen, Matti Grönroos, and Christina Salmivalli \\ University of Turku
}

\begin{abstract}
The objective of the present research was to develop an assessment model for children's social goals. The aims were (a) to fit children's social goals to a circumplex model and to examine links between goals and peer-reported social behaviors (aggression, withdrawal, and prosocial behavior) in a sample of 276 participants (134 girls, 11- to 12-year-olds) and (b) to replicate these findings and examine whether social behavior mediates the relationship between goals and sociometric status in an independent cross-validation sample of 310 participants (143 girls, 11- to 13-year-olds). Results showed a satisfactory fit to the circumplex model and adequate psychometric properties of the goal scales of the new measure, the Interpersonal Goals Inventory for Children. Other findings included significant and meaningful relations between goals and peer-reported behavior. Social behavior mediated the relations between goals and sociometric status.
\end{abstract}

Keywords: social goals, social adjustment, interpersonal circumplex, agency, communality

Over the past few decades, much of the research on children's social adjustment has focused on social skills. However, some aggressive children, for instance, are efficient in using both coercive and prosocial strategies with peers (i.e., "bistrategic controllers;" see Hawley, 2003), have good theory of mind skills (Sutton, Smith, \& Swettenham, 1999), and are not necessarily rejected but may be popular among their peers (Luthar \& McMahon, 1996; Rodkin \& Farmer, 2000). Although these findings challenge the "social skill deficit view" of aggressive behavior, increasing information about children's social goals (e.g., Erdley \& Asher, 1996; Renshaw \& Asher, 1983) suggests that motivational factors account for additional variance in social adjustment.

However, considerable variation in children's goal categories across studies makes it difficult to formulate a broader view on how social goals relate to children's social adjustment. Prior research has examined, for instance, positive-outgoing, positiveaccommodating, rule-oriented, avoidance, and hostile goals (Renshaw \& Asher, 1983); relationship, control, self-interest, and avoidance goals (Chung \& Asher, 1996); and relationship, control, tension reduction, instrumental, moral, and revenge goals (Rose \& Asher, 1999). Our objective was to explicate an overarching framework and an assessment strategy for examining the general structure of children's social goals.

Tiina Ojanen and Christina Salmivalli, Department of Psychology, University of Turku, Turku, Finland; Matti Grönroos, Department of Statistics, University of Turku.

This study was part of Project 202554/68884, "Relational Schemas, Social Goals, and Social Adjustment in Childhood and Adolescence," funded by The Academy of Finland. This study was also supported by the Finnish Graduate School of Psychology. We are grateful to David Perry, Kätlin Peets, and Jenny Isaacs for their valuable criticism and comments on earlier versions of this article. We also thank Jemina Haanpää, Virpi Pöyhönen, Nina Rajainmäki, and Sani Väänänen for their help in data collection and Jacqueline Välimäki for editorial assistance.

Correspondence concerning this article should be addressed to Tiina Ojanen, Department of Psychology, University of Turku, FIN-20014, Turku, Finland. E-mail: tiina.ojanen@utu.fi

\section{Theories and Development of Social Goals}

Theories of social goals have developed within the cognition, motivation, and personality literatures (see Austin \& Vancouver, 1996, for a review). From the social-cognitive perspective, goals are assumed to motivate behaviors because behavioral strategies are generated, evaluated, and selected, in part, on the basis of the desired outcome (i.e., goal) for the situation (Crick \& Dodge, 1994). Social motives or needs ultimately form two major clusters: motives directed toward gaining agency, or power, and motives related to gaining communion, or affiliation and intimacy with others (Buhrmester, 1996). We therefore considered the interpersonal circumplex model (e.g., Gurtman, 1992; Kiesler, 1983) as an appropriate theoretical framework for children's interpersonal goals (i.e., goals targeted for attaining, maintaining, or avoiding specific end states for self in relation to peers; see Fitzsimons \& Bargh, 2003). In this framework (see Locke, 2000), interpersonal goals may be described as organized around the dimensions of agency, reflecting authority and appearing confident (agency) versus avoiding arguments and anger by going along with others' expectations (submission), and communality, reflecting the striving for closeness and affiliation with others (communality) versus concealing one's thoughts and feelings (separation).

Many goal categories already used in children's research enfold around the dimensions of agency and communality. Jarvinen and Nicholls (1996) assessed as well agentic (dominance and leadership) and communal (intimacy and nurturance) goals. In addition, relationship (Chung \& Asher, 1996) and relationship maintenance goals (Erdley \& Asher, 1996) encompass communality, whereas control goals (Chung \& Asher, 1996) and the goals of maintaining an assertive reputation (Erdley \& Asher, 1996) reflect agency. The general framework of friendliness and assertiveness by Renshaw and Asher (1983) also comes very close to the agentic/communal approach: Their positive-accommodating goals encompass both assertiveness and friendliness (i.e., agentic and communal dimensions), whereas hostile goals compose a highly assertive quality but lack friendliness (i.e., can be thought of as high on the agentic dimension but low on the communal dimension). 
Agency and communality constitute orthogonal dimensions of interpersonal dispositions in adults (Locke, 2000) and are likely to develop into differentiated motives apparent already by adolescence, where goals for intimacy and dominance load on distinct factors and have divergent correlates (Jarvinen \& Nicholls, 1996). According to Hawley (2002), coercive and prosocial strategies of 3 - to 6-year-olds are associated with each other and have no distinct relations with social motivational correlates (suggesting that these strategies are not well differentiated at this stage). However, coercive and prosocial strategies of third through sixth graders have distinct relations with constructs reflecting agentic and communal motives. Coercive controllers have high needs for social recognition and instrumental motivations for forming friendships, whereas children who use prosocial strategies place more importance on friendships and are intrinsically motivated to form them (Hawley, Little, \& Pasupathi, 2002). Furthermore, given that adolescents' social motives focus on gaining status on the one hand (Pellegrini \& Long, 2002) and seeking closeness and intimacy with peers on the other (Buhrmester, 1990), preadolescents are likely to pursue increased levels of agentic and communal goals with peers over time.

As described by Crick and Dodge (1994), children enter peer situations with relatively stable, traitlike goal orientations and revise their goals and construct new ones in response to immediate social stimuli. In contrast to goals evoked and shaped by situational cues, we focused on children's global goal orientations, regarded as latent mental structures of past social experiences (Crick \& Dodge, 1994), or as underlying social needs (see Buhrmester, 1996), assumed to influence online information processing. It should be noted that this does not preclude the possibility that goals vary according to the cues provided by specific situations and/or interaction partners-we believe that they do. However, in order to study situational variability, one needs to have a general framework for measuring goals. Only a broad conceptual approach can allow investigators to study goals across contexts instead of measuring entirely different goals for each situation (Asher, 2004).

\section{Methods for Assessing Social Goals}

Children's social goals have been traditionally assessed with open-ended interviews by asking children "What would you be trying to do" or "Why are you doing or saying that?" (the response the child mentioned before) in hypothetical situations (e.g., Chung \& Asher, 1996; Erdley \& Asher, 1996). The advantage of the interview method is that the goals selected, or produced by children, represent, in fact, relevant and salient goals for them. However, it is difficult to separate the development of goals from the development of response strategies, or general cognitive maturation. More recently, pen-and-paper inventories have been used in the research with importance ratings of various alternative goals (e.g., Lemerise, Trame, \& Crafton, 2003; Rose \& Asher, 1999; Underwood \& Bjornstad, 2001). Because adaptive social interactions are likely to require the coordination and management of multiple goals at the same time (Dodge, Asher, \& Parkhurst, 1989), inventories entailing subjective importance ratings provide an effective method for gleaning information about goals that one may pursue simultaneously as well as about developmental shifts in goals over time. However, these inventories have typically included a problem-driven selection of goals (e.g., goals related to aggression or to other specific topics of interest) rather than items representing a comprehensive range of interpersonal dispositions.

In adults, the Interpersonal Goals Inventory (IGI; Dryer \& Horowitz, 1997) and the Circumplex Scales of Interpersonal Values (CSIV; Locke, 2000) were both developed on the basis of the interpersonal circumplex model. Interpersonal dispositions in the circumplex may be conceptualized along the following scales: Agentic ( $+\mathrm{A}$; appearing self-confident and being admired by others), Agentic and Communal $(+\mathrm{A}+\mathrm{C}$; expressing oneself openly, being heard), Communal $(+\mathrm{C}$; feeling closeness to the others and developing true friendships with them), Submissive and Communal $(-\mathrm{A}+\mathrm{C}$; seeking others' approval by complying with their opinions), Submissive (-A; avoiding making others angry by pleasing them), Submissive and Separate $(-\mathrm{A}-\mathrm{C}$; avoiding social embarrassment), Separate $(-\mathrm{C}$; appearing detached, without revealing one's thoughts and feelings), and Agentic and Separate ( $+\mathrm{A}-\mathrm{C}$; being in control, having no interest in others' opinions). Our Interpersonal Goals Inventory for Children (IGI-C) included these eight scales (see Figure 1). The circumplex structure enables the assessment of a full range of interpersonal goals and thus permits the formulation of predictable hypotheses in relation to various adjustment indexes. The model includes goals similar to those previously associated with aggression and hostile/coercive strategies (agentic, or separate and agentic goals), prosocial behavior and strategies (communal goals), and social withdrawal (separate and submissive goals).

\section{Social Goals and Social Adjustment}

Children's social goals are associated with their social behavior and sociometric status. Aggressive children, for instance, endorse more antisocial goals than their nonaggressive peers (Erdley \& Asher, 1996; Lochman, Wayland, \& White, 1993). Proactively aggressive children tend to select instrumental over relational goals in conflict situations more often than their nonaggressive peers (Crick \& Dodge, 1996). Erdley and Asher (1996) examined whether children who vary in their behavioral responses to ambiguous provocation (i.e., aggressive, withdrawn, and prosocial responses), but are similar in their attributional processes, differ in their social goals. Aggressive children in both hostile and benign intent groups were characterized by antisocial goals (such as getting back at the protagonist, looking strong, and protecting oneself) and differed from both withdrawn and prosocial children, who pursued more similar prosocial goals.

According to the social information model by Crick and Dodge (1994), goals are associated with social feedback via social strategies and social behaviors. There is empirical support for this pattern. For instance, control goals (i.e., having control over one's activities, possessions, or personal space) in conflict situations predict hostile and coercive strategies, which, in turn, relate to low peer acceptance, at least for girls (Chung \& Asher, 1996). Relationship goals (i.e., maintaining a good relationship with others) and positive-outgoing goals (being high on both friendliness and assertiveness), in turn, relate to prosocial strategies and social acceptance (Chung \& Asher, 1996; Renshaw \& Asher, 1983). Given the more proximal links between goals and behavior, it seems plausible that children's goals would contribute to certain behavior patterns, which would then influence their peers' perceptions of them. The findings of Wentzel and Erdley (1993) sup- 


\title{
How important is it for you that
}

\author{
"The others respect and admire you."
}

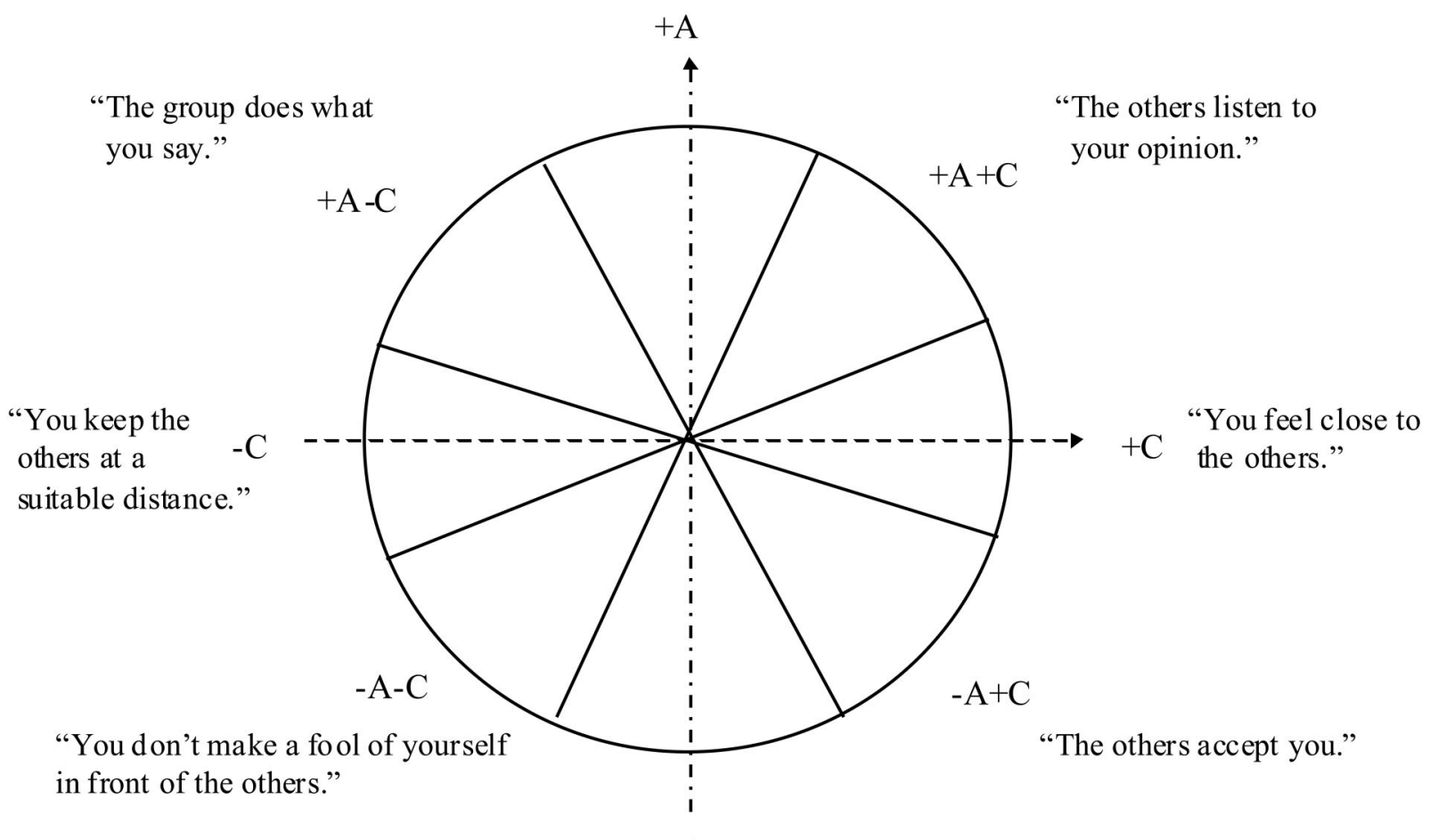

$-\mathrm{A}$

"You don’t annoy the others."

Figure 1. The placement of the interpersonal goal scales in the circumplex model, followed by an example item from each of the eight scales. $+\mathrm{A}=$ Agentic; $+\mathrm{A}-\mathrm{C}=$ Agentic and Separate; $+\mathrm{A}+\mathrm{C}=$ Agentic and Communal; $-\mathrm{C}=$ Separate; $+\mathrm{C}=$ Communal; $-\mathrm{A}-\mathrm{C}=$ Submissive and Separate; $-\mathrm{A}+\mathrm{C}=$ Submissive and Communal; $-\mathrm{A}=$ Submissive

ported this sequential view: Social behavior mediated the relation between children's strategy knowledge and their peer acceptance.

\section{Aims and Hypotheses of the Present Study}

Our first aim was to evaluate the psychometric properties of the IGI-C and to test the fit of children's social goals to the interpersonal circumplex model in two independent samples. Fitting children's social goals into the interpersonal circumplex model, adopted from adults, was considered to indicate that similar constructs may be used to assess social goals in preadolescence and adulthood, which would allow investigators to take a broader life span perspective on interpersonal goal strivings. Given that the striving for belongingness (reflecting communion with others) is a fundamental human motivation (see Baumeister \& Leary, 1995, for a review; Waldinger et al., 2002), communal goals were expected to have a predominant role over agentic goals in preadolescence as well. Because boys are socially direct, self-assertive, and endorse more control goals than girls, who, in turn, have more enabling interaction styles (i.e., ac- knowledge others and express agreement) and relationship-oriented goals than boys (Chung \& Asher, 1996; Jarvinen \& Nicholls, 1996; Rose \& Asher, 1999; see also Maccoby, 1990, for a review), boys were expected to score higher on agentic goals than girls, who, in turn, were expected to endorse more communal goals than boys.

Second, we wanted to test whether social behavior mediates the relation between social goals and sociometric status, as hypothesized (Erdley \& Asher, 1996). Agentic goals (goals that reflect the aim to be admired and respected by others, and having control over peer-group activities) were expected to be related to aggression and, consequently, to peer rejection. Communal goals (goals encompassing the aim for closeness) were expected to be associated with prosocial behavior, which, in turn, was expected to be associated with peer acceptance. Finally, withdrawal was expected to be associated with the lack of communal goals (reflecting the aim toward social separation). A mediational model, concerning children's goals, behavior, and sociometric status, was considered to provide further validation for the IGI-C goal scales and to con- 
tribute to a more comprehensive picture of the underlying social motivational influences on children's social adjustment.

Research on children's goals has typically been cross-sectional (e.g., Chung \& Asher, 1996; Rose \& Asher, in press), and documentation of development in goals over time, including the identification of crucial transition periods influencing basic interpersonal concerns and needs, has been called for (Buhrmester, 1996). Our final aim was, therefore, to investigate short-term developmental patterns in goals. Given that social concerns in adolescence focus on gaining status (reflecting agency) as well as intimacy (reflecting communality) with peers (e.g., Buhrmester, 1990; Pellegrini \& Long, 2002), we expected preadolescents to pursue increased levels of both agentic and communal goals over time.

\section{Method}

\section{Participants}

The participants were recruited from eight schools in a medium-sized (approximately 170,000 inhabitants) town in southwest Finland. Two independent samples were used in the study, referred to as primary and cross-validation samples. Schools and classrooms in both samples were randomly selected. To examine goal patterns over time, children in both samples were met with twice in 1 year (in addition to a 2-week test-retest assessment in the primary sample). At Time 1 , children were fifth and sixth graders (11- to 13-year-olds), whereas at Time 2, they were sixth and seventh graders (12- to 14-year-olds). The participants thus represented the age range in which children are considered to have the cognitive ability to reflect on their goals (Chung \& Asher, 1996). Information concerning the participants' socioeconomic status (SES), ethnicity, or family structure was not available.

Primary sample. The original data pool consisted of 295 children from 12 classes (fifth and sixth graders) from four Finnish elementary schools. Several weeks before the data collection, letters giving a description of the project, along with passive consent forms, were sent to parents. Five children $(1.7 \%)$ did not receive parental consent to participate and were excluded from the study. Twelve children were not present for other reasons (e.g., were sick) at the time of the data collection, and self-reports from 2 children were inadequate. To assess test-retest reliability of the goal scales, participants were met with again after 2 weeks. The final sample consisted of 276 participants (134 girls, 11- to 12-year-olds,) who were in fifth ( $n=143,65$ girls $)$ and sixth $(n=133,69$ girls $)$ grades, of whom 256 were present 2 weeks later for the test-retest measure. Class sizes varied between 19 and 29, with a mean size of 25 students.

Cross-validation sample. The original data pool for the crossvalidation sample consisted of 351 children from 14 classes (fifth and sixth graders) from a Finnish elementary school. Again, passive consent forms and letters providing a description of the project were sent to parents. Two children $(0.6 \%)$ were thereby excluded from the study. Because 38 children were absent at the time of the data collection, and one self-report was inadequate, the final sample consisted of 310 participants (143 girls, 11- to 13 -year-olds $)$ in the fifth $(n=127,51$ girls $)$ and sixth $(n=183,92$ girls $)$ grades. Class sizes ranged from 15 to 34 , with a mean of 25 students.

Attrition. For various reasons (moves, absences, parental refusal for participation), complete data sets were not available from all participants at all assessment points. In the primary sample, Time 2 agentic goal scores could be calculated for 245 (89\%) participants and communal scores could be calculated for 203 (74\%) participants. In the cross-validation sample, Time 2 agentic vector scores were available for $268(86 \%)$ participants and communal scores for $220(71 \%)$ participants. Dropouts were mostly children who were in the sixth grade during the first assessment ( $n=133$ in the primary sample, $n=183$ in the cross-validation sample). They were more difficult to trace for the third assessment because the transition from the sixth to the seventh grade involves changing from the lower (1-6) to the upper (7-9) elementary school, during which time children disperse to various schools. Attrition analysis indicated that in the primary sample, participants absent from the Time 2 measurement did not differ in their initial levels of agentic or communal goals from those present at Time 2 . In the cross-validation sample, however, participants absent from Time 2 scored higher in the initial assessment in both agentic $(p<.05)$ and communal $(p<.05)$ goals

\section{Procedure}

For both samples, data collection took place in classrooms during school hours and followed the same procedure. In each session, two research assistants supervised the testing. The sessions started with an introduction to the project, with emphasis on the confidentiality of the study. Instructions were written on the questionnaires and also read out loud and explained to the children. Children were encouraged to ask advice from the supervising assistants if they had any problems comprehending the questions. It took approximately $1 \mathrm{hr}$ for children to complete all the questionnaires. Data for other purposes were also collected. The order of the questionnaires was counterbalanced across classrooms.

\section{Measures}

Social goals and social behavior were assessed in both samples. However, the information on sociometric status was available only in the cross-validation sample.

Social goals. Development of the scales for the IGI-C was based on the Circumplex scales of the Interpersonal Values (CSIV) measure by Locke (2000). The assessed goals represented different blends of agentic (reflecting the aim for assertiveness and admiration) and communal (reflecting the aim for closeness with others) goals. The scaling and example items of the IGI-C are provided in Figure 1. We sought to generate items that were either identical (when appropriate) to the items of the CSIV or similar in content but applied to children. A complete list of items (translated into English by a professional translator, who is also a native speaker of English) is given in the Appendix.

Goals were assessed by presenting children with a list of 33 alternative interpersonal outcomes in a questionnaire. ${ }^{1}$ The instruction was, "When with your age-mates, how important is it for you that ..." Children evaluated each item using Likert scalelike ratings ranging from 0 (no importance for me at all) to 3 (very important to me).

The eight goal scales were used to assess the basic psychometric properties of the measure (for the complete list of items in each scale, see the Appendix). In addition, to obtain an overall score for agentic and communal goal dimensions, agentic and communal vector scores were calculated for each child, following a procedure used by Locke (2003) (originally provided by Wiggins, Phillips, \& Trapnell, 1989): ${ }^{2}$

$$
\begin{aligned}
& \text { Agentic }_{\text {vect }}=\text { Agentic }- \text { Submissive }+[.707 \\
& \quad \times(\text { Agentic and Communal }+ \text { Agentic and Separate } \\
& - \text { Submissive and Communal }- \text { Submissive and Separate })] .
\end{aligned}
$$

${ }^{1}$ A pilot study was conducted in Spring 2002 on a sample of 70 children (11- to 12-year-olds). The inventory used in the pilot study consisted of 42 items. On the basis of the reliability assessment, however, the final inventory was modified to include 33 items forming eight goal scales, with 3-6 items per scale.

${ }^{2}$ The reason for multiplying the scores on the four intermediate scales (Agentic and Communal, Submissive and Communal, Agentic and Separate, Submissive and Separate) by .707 is that .707 is the cosine of a $45^{\circ}$ angle (the angle of those scales, or octants of the circumplex, relative to the agentic and communal vectors). 
Communal $_{\text {vect }}=$ Communal - Separate $+[.707$

$$
\begin{gathered}
\times \text { (Agentic and Communal }+ \text { Submissive and Communal } \\
- \text { Agentic and Separate }- \text { Submissive and Separate })] .
\end{gathered}
$$

In accordance with the theoretical assumptions, agentic and communal vector scores formed two orthogonal dimensions, with a bivariate correlation close to zero $(.09, n s)$ in the primary sample. In the cross-validation sample, the vector scores were weakly correlated $(-.14)$.

Social behavior. To validate the instrument (IGI-C), a peer nomination inventory concerning social behavior was administered to the children. In the questionnaire, children checked off the names of both same- and other-sex classmates who manifested the behavior described in each of the nine items. The items encompassed three types of behaviors: aggression (harasses others on purpose, dominates and forces others to do as $\mathrm{s}$ (he) wishes, embarrasses others for no reason), withdrawal (likes to spend time on his or her own, withdraws outside the group, is timid and shy), and prosocial behavior (is friendly toward the others, really tries to ensure that everybody has fun, helps the others). Scores for each type of behavior were calculated by summing the number of nominations each child received for each item, dividing them by the number of nominators in each class at the time of the data collection, and computing sum scores for the three items (final scores thus ranging from 0.00 to 3.00 ). All the scale internal consistencies were high $(\alpha \mathrm{s}=.79-.91)$.

Sociometric status. Data concerning children's social status were available in the cross-validation sample. Sociometric status was assessed by asking children to write down the names of the three classmates they liked most and the three classmates they liked least. The number of liked-most and liked-least nominations was calculated for each child and standardized within classes.

\section{Results}

\section{Descriptive Statistics}

Means and standard deviations of the measures for both samples are presented in Table 1. As indicated by the agentic and communal vector scores, children scored higher on communal than on agentic goals in the primary sample, $t(275)=31.46, p<.001$, as well as in the cross-validation sample, $t(309)=28.60, p<.001$. In addition, girls displayed higher degrees of communal goals than boys in the primary, $t(274)=5.71, p<.001$, as well as in the cross-validation sample, $t(308)=6.63, p<.001$. In the primary sample, boys endorsed higher degrees of agentic goals, as expected, $t(274)=2.01, p<.05$. The difference was in the same direction in the cross-validation sample as well but did not reach significance, $t(308)=1.34, p=.18$.

Because of the hierarchical nature of our data (students nested within classrooms), we tested whether there were any clustering effects of classrooms on children's social goal scores. This was done by using the Mplus statistical package, Version 2.14 (Múthen \& Múthen, 1998-2001). Using multilevel modeling, the clustering effects (on the measures of interest) can be assessed by separating the variance between different school classes from the variance between individual children within the classes. In both samples, the intraclass correlations indicating the proportion of the variance caused by variation between different classrooms were practically zero. Social goals therefore varied between individual children but not between classrooms.

\section{Reliability of the IGI-C}

Internal consistency. Internal consistencies of the scales were mostly satisfactory. In the first sample, only for one scale was the Cronbach's alpha coefficient below .68 (Submissive and Communal, $\alpha=.57$; see Table 2). Otherwise, the alphas ranged from .68 to .73. A similar pattern of findings was obtained in the second sample: The alpha for the Submissive and Communal scale was .63 , whereas alphas otherwise ranged from .68 to .82 , usually above .70 .

Test-retest reliability. To assess test-retest reliability of the IGI-C scales, participants of the first sample completed the inventory again 2 weeks after the initial assessment. Zero-order corre-

Table 1

\begin{tabular}{|c|c|c|c|c|c|c|c|c|}
\hline \multirow[b]{3}{*}{ Measure } & \multicolumn{4}{|c|}{ Primary sample } & \multicolumn{4}{|c|}{ Cross-validation sample } \\
\hline & \multicolumn{2}{|c|}{$\begin{array}{c}\text { Boys } \\
(n=142)\end{array}$} & \multicolumn{2}{|c|}{$\begin{array}{c}\text { Girls } \\
(n=134)\end{array}$} & \multicolumn{2}{|c|}{$\begin{array}{c}\text { Boys } \\
(n=167)\end{array}$} & \multicolumn{2}{|c|}{$\begin{array}{c}\text { Girls } \\
(n=143)\end{array}$} \\
\hline & $M$ & $S D$ & $M$ & $S D$ & $M$ & $S D$ & $M$ & $S D$ \\
\hline \multicolumn{9}{|l|}{ Goal scale (ipsatized ${ }^{\mathrm{a}}$ ) } \\
\hline Agentic & -0.27 & 0.50 & -0.34 & 0.67 & -0.25 & 0.49 & -0.28 & 0.53 \\
\hline Agentic and Communal & 0.15 & 0.39 & 0.24 & 0.51 & 0.09 & 0.45 & 0.31 & 0.48 \\
\hline Communal & 0.41 & 0.44 & 0.76 & 0.46 & 0.34 & 0.45 & 0.71 & 0.45 \\
\hline Submissive and Communal & 0.32 & 0.33 & 0.36 & 0.35 & 0.38 & 0.34 & 0.39 & 0.40 \\
\hline Submissive & 0.37 & 0.42 & 0.55 & 0.47 & 0.43 & 0.46 & 0.56 & 0.44 \\
\hline Submissive and Separate & 0.08 & 0.54 & 0.00 & 0.59 & 0.04 & 0.57 & -0.05 & 0.60 \\
\hline Separate & -0.27 & 0.52 & -0.55 & 0.49 & -0.37 & 0.48 & -0.65 & 0.56 \\
\hline Agentic and Separate & -0.78 & 0.50 & -1.02 & 0.44 & -0.66 & 0.59 & -1.01 & 0.51 \\
\hline \multicolumn{9}{|l|}{ Vector score } \\
\hline Agentic & -1.38 & 1.28 & -1.70 & 1.28 & -1.38 & 1.28 & -1.57 & 1.23 \\
\hline Communal & 1.51 & 1.34 & 2.45 & 1.39 & 1.50 & 1.36 & 2.61 & 1.57 \\
\hline \multicolumn{9}{|l|}{ Behavior } \\
\hline Aggression & 0.23 & 0.34 & 0.14 & 0.22 & 0.29 & 0.38 & 0.17 & 0.28 \\
\hline Withdrawal & 0.16 & 0.27 & 0.22 & 0.34 & 0.21 & 0.29 & 0.26 & 0.37 \\
\hline Prosocial & 0.62 & 0.49 & 0.88 & 0.47 & 0.66 & 0.45 & 0.93 & 0.43 \\
\hline
\end{tabular}

Mean Ratings and Standard Deviations of the Measures Included in Both Samples

${ }^{\text {a }}$ Scores expressed as deviations from their mean score across all the scales. 
Table 2

Intercorrelations Among the (Ipsatized ${ }^{\mathrm{a}}$ ) Interpersonal Goal Scales Along With the Alpha Coefficients for Each Scale

$\alpha$

\begin{tabular}{|c|c|c|c|c|c|c|c|c|c|c|}
\hline IGI-C scale & 1 & 2 & 3 & 4 & 5 & 6 & 7 & 8 & Primary sample & Cross-validation sample \\
\hline 1. $+\mathrm{A}$ & - & -.11 & $-.27 * * *$ & $-.31 * * *$ & $-.31 * * *$ & $.17^{* * *}$ & $-.12 *$ & $.17 * *$ & .70 & .74 \\
\hline 2. $+\mathrm{A}+\mathrm{C}$ & -.04 & - & $.26 * * *$ & .01 & .08 & $-.40 * * *$ & $-.41 * * *$ & $-.21 * * *$ & .68 & .75 \\
\hline 3. $+\mathrm{C}$ & $-.17 * *$ & $.23 * * *$ & - & $.37 * * *$ & $.34 * * *$ & $-.35^{* * * *}$ & $-.51 * * *$ & $-.48 * * *$ & .73 & .79 \\
\hline 4. $-\mathrm{A}+\mathrm{C}$ & $-.33 * * *$ & .06 & $.35 * * *$ & - & $.17 *$ & $-.31 * * *$ & $-.24 * * *$ & $-.26 * * *$ & .57 & .63 \\
\hline 5. $-\mathrm{A}$ & $-.31 * * *$ & $-.24 * * *$ & .10 & .10 & - & -.10 & $-.40 * * *$ & $-.50 * * *$ & .68 & .82 \\
\hline 6. $-\mathrm{A}-\mathrm{C}$ & $-.26 * * *$ & $-.45 * * *$ & $-.45 * * *$ & $-.30 * * *$ & .07 & - & $.24 * * *$ & $-.17 * *$ & .70 & .78 \\
\hline 7. $-\mathrm{C}$ & $-.20 * *$ & $-.38 * * *$ & $-.51 * * *$ & $-.30 * * *$ & $-.14 *$ & $.31 * * *$ & - & $.17 * *$ & .69 & .82 \\
\hline 8. $+\mathrm{A}-\mathrm{C}$ & $.21 * *$ & -.03 & $-.32 * * *$ & $-.21 * *$ & $-.50 * * *$ & $-.21 * *$ & -.01 & - & .72 & .80 \\
\hline
\end{tabular}

Note. $\quad$ IGI-C $=$ Interpersonal Goals Inventory for Children; Interpersonal Goal scales: $+\mathrm{A}=\mathrm{Agentic} ;+\mathrm{A}+\mathrm{C}=\mathrm{Agentic}$ and $\mathrm{Communal} ;+\mathrm{C}=$ Communal; $-\mathrm{A}+\mathrm{C}=$ Submissive and Communal; $-\mathrm{A}=$ Submissive $;-\mathrm{A}-\mathrm{C}=$ Submissive and Separate; $-\mathrm{C}=$ Separate; $+\mathrm{A}-\mathrm{C}=\mathrm{Agentic}$ and Separate. Correlations for the primary sample $(n=276)$ are reported below the diagonal, and correlations for the cross-validation sample $(n=310)$ are reported above the diagonal. Correlations between the opposite scales of the circumplex are shown in bold.

${ }^{a}$ Scores expressed as deviations from their mean score across all the scales.

$* p<.05$. ** $p<.01$. **** $p<.001$.

lations indicated adequate stability for the goal scales: .65 for the $+\mathrm{A}$ scale, .59 for the $+\mathrm{A}+\mathrm{C}$ scale, .61 for the $+\mathrm{C}$ scale, .59 for the $-\mathrm{A}+\mathrm{C}$ scale, .60 for the $-\mathrm{A}$ scale, .74 for the $-\mathrm{A}-\mathrm{C}$ scale, .70 for the $-\mathrm{C}$ scale, and .63 for the $+\mathrm{A}-\mathrm{C}$ scale, all significant at the .001 level. In addition, correlations among the vector scores across the 2-week period $(r=.55, p<.001$, for agentic scores; $r$ $=.73, p<.001$, for communal scores) provided further evidence of the test-retest reliability of the IGI-C.

\section{Construct Validity: Fit of the Circumplex Model}

The eight goal scales were examined in relation to the circumplex structure in the manner used in previous research (e.g., Locke, 2000). Participants' responses to the items were first ipsatized (i.e., expressed as deviations from their mean score across all the scales in order to control for the variation in subjective response style). This procedure is commonly used in assessing the circumplex properties of interpersonal measures in adults (see Locke, 2000). On the basis of the circumplex model, we expected that the highest positive correlations would be observed between adjacent octants or scales (e.g., between the Agentic scale and the Agentic and Separate scale) and the highest negative correlations between the polar opposite octants or scales (e.g., between the Communal scale and the Separate scale).

Overall, intercorrelations among the ipsatized goal scales in both samples (see Table 2) indicated circular ordering. Scale intercorrelations were subjected to principal-components analysis, in which the agentic and communal dimensions explained $54 \%$ of the variance in the first sample. The placement of the goal scales on the basis of their loadings on the agentic and communal factors (rotation varimax) in the first sample are presented in Figure 2.

To evaluate the fit between our goal scales and the circumplex model, we used the randomization test of hypothesized order relations (Hubert \& Arabie, 1987). The analysis was conducted with the program RANDALL (Tracey, 1997; see also Locke, 2000). The scale intercorrelations were used as input for the analysis. The program assesses the fit of the circumplex structure by computing 288 predictions about the relative magnitudes of correlations among the scales, a correspondence index (CI; Hubert $\&$ Arabie, 1987) that describes the fit of the theoretical assump- tions in the empirical data, and the exact probability that the observed fit would occur by chance (by comparing the observed fit with the distribution of fit obtained from all possible permutations of the rows and columns of the correlation matrix). Perfect fit of the circular model would require that the correlations of the adjacent scales (octants) of the circle exceed the correlations of scales two octants apart, which, in turn, must exceed those of scales three octants apart, which, in turn, must exceed those of opposite scales on the circle. The CI is equal to the proportion of predictions met minus the proportion violated. The range of the $\mathrm{CI}$ is from -1.0 (all predictions violated) to 0.0 (chance, or $50 \%$ of predictions met) to 1.0 (perfect fit).

We assessed the fit between the goal scales and the circumplex structure separately in two waves of data in the first sample and cross-validated the fit in the second sample. In the first sample, data from the first measurement indicated that 262 of the 288 predictions were met, with $\mathrm{CI}>.82(p<.001)$. The data from the second measurement 2 weeks later still showed a promising fit of the model but with a slightly lower level of correspondence: 248 of the 288 predictions were met with $\mathrm{CI}>.73(p<.001)$. The results in the cross-replication sample indicated that 244 of the total of 288 predictions were met, with $\mathrm{CI}>.69(p<.001)$.

Finally, we explored possible gender differences in the model fit by assessing the fit separately for boys and girls. In both samples, the fit was relatively similar for boys and girls. The CIs for boys and girls, respectively, were $>.78(p<.001)$ and $>.74(p<.05)$ in the primary sample and $>.67(p<.001)$ and $>.61(p<.05)$ in the cross-validation sample.

\section{Criterion Validity: Associations With Peer-Reported Behavior and Sociometric Status}

To assess the criterion validity of the instrument, eight goal scales, as well as agentic and communal vector scores, were correlated with peer-reported social behaviors (see Table 3). Because the behavior variables were not normally distributed, Spearman rank-order correlations were used. The pattern of correlations was meaningful and largely consistent between the primary and the cross-validation sample. The strongest associations were observed between goals and prosocial behavior in both samples. 


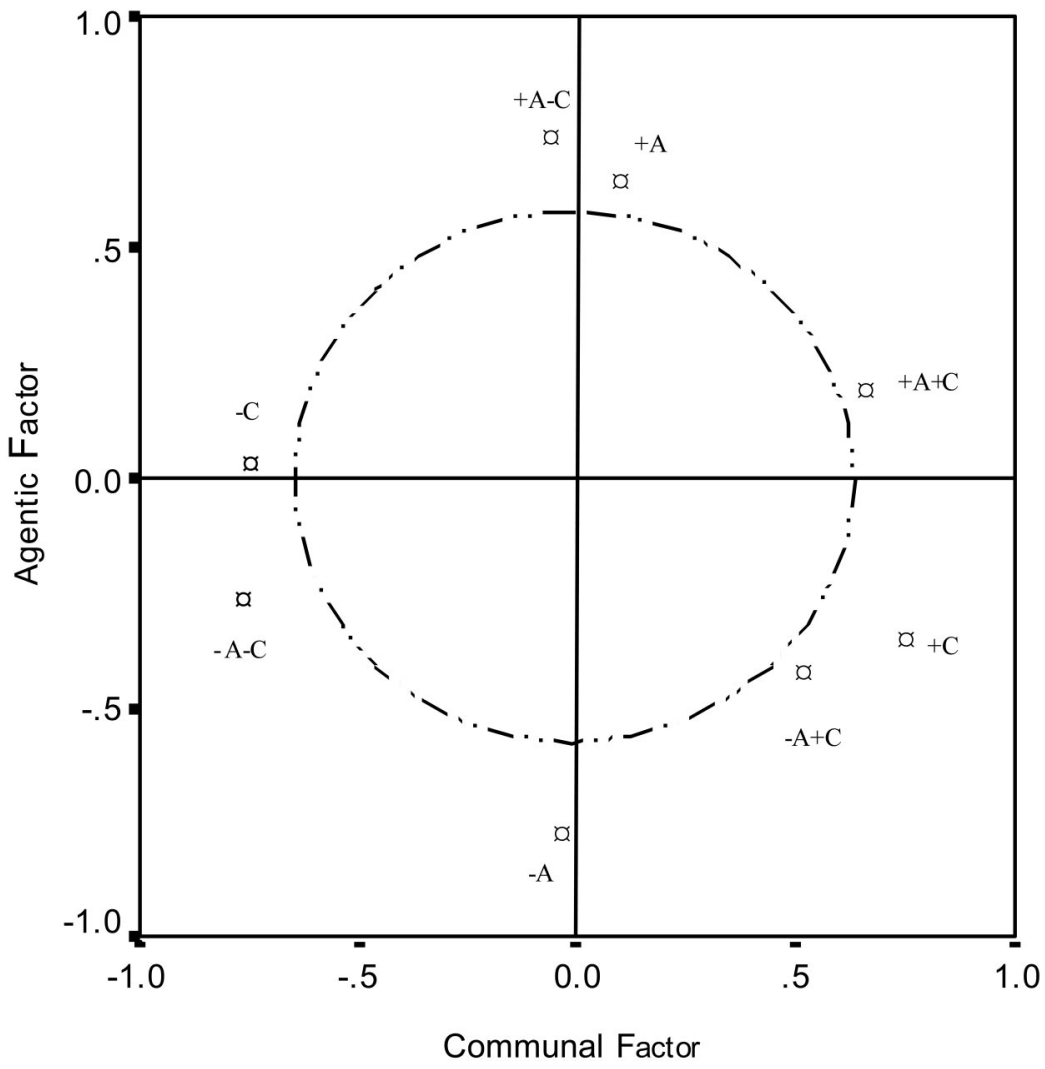

Figure 2. Circumplex structure of the Interpersonal Goals Inventory for Children scales $(N=276)$. The solution rotated so that Agentic scale $(+\mathrm{A})$ is at $90^{\circ} .+\mathrm{A}-\mathrm{C}=$ Agentic and Separate; $-\mathrm{C}=$ Separate; $+\mathrm{A}+\mathrm{C}=$ Agentic and Communal; $-\mathrm{A}-\mathrm{C}=$ Submissive and Separate; $+\mathrm{C}=$ Communal; $-\mathrm{A}+\mathrm{C}=$ Submissive and Communal; $-\mathrm{A}=$ Submissive.

Prosocial behavior was positively related to Communal, Submissive-Communal, and Submissive goal scales as well as to communal vector scores. Aggression was positively associated with the Agentic-Separate goal scale and agentic vector scores. Finally, withdrawal was related to the Submissive-Separate goal scale as well as to low scores on the agentic vector.

Connections with sociometric status. The data set available in the cross-validation sample enabled us to test the hypothesis that the relation between children's social goals and sociometric status would be mediated by their social behavior. For testing the mediator hypothesis, a path analysis was carried out. Model estimation was conducted with the estimator MLM that computes maximumlikelihood parameter estimates, with robust standard errors and mean-adjusted chi-square statistics (Múthen \& Múthen, 1998-2001).

Following our hypotheses, the model estimation was begun by constructing a model that included paths from agentic goals to peer rejection via aggression and withdrawal behaviors and from communal goals to peer acceptance via prosocial and withdrawal behaviors. The path from agentic goals to withdrawal was estimated because the correlations between goals and behaviors (see Table 3) indicated even stronger negative association between agentic goals and withdrawal than between communal goals and withdrawal. Gender was included in the model to control for its effects on goals as well as on social behaviors. Error variances between gender and social goals, between the three behavior variables, as well as between peer acceptance and rejection were allowed to covary. Model fit was estimated with a chi-square test, the comparative fit index (CFI), and the root-mean-square error of approximation (RMSEA).

The tested model had a poor fit to the data, $\chi^{2}(11)=80.15$, $p=.00$, RMSEA $=.14, \mathrm{CFI}=.82$, and included a nonsignificant path from agentic goals to withdrawal $(\beta=-.06)$. After omitting this path, the model fit was still below satisfactory, $\chi^{2}(12)=81.39, p=.00$, RMSEA $=.14, \mathrm{CFI}=.82 ;$ and the modification indexes suggested that paths from agentic goals to prosocial behaviors, from aggression and withdrawal to peer acceptance, and from prosocial behavior to peer rejection should be included in the model. The final model had a good fit to the data, $\chi^{2}(8)=6.61, p=.58, \mathrm{RMSEA}=.00, \mathrm{CFI}=1.00$ As can be seen in Figure 3, aggression was associated with agentic goals; prosocial behavior, with high degrees of communal goals and low degrees of agentic goals; and withdrawal, with low degrees of communal goals. Prosocial behavior was positively related to peer acceptance and negatively related to social rejection, whereas aggression and withdrawal were positively associated with peer rejection and negatively associated with peer acceptance. Because the gender variable was coded as $0=$ girl, 1 = boy, a negative path coefficient from gender to another variable in Figure 3 indicates higher scores for girls than for boys on that variable. The significant correlation between gender and communal goals indicated that girls endorsed 
Table 3

Zero-Order (Spearman) Correlations of the IGI-C Goal Scales and Vector Scores With Peer-Reported Social Behaviors for the Primary and the Cross-Validation Sample

\begin{tabular}{|c|c|c|c|c|c|c|}
\hline \multirow[b]{3}{*}{ Measure } & \multicolumn{6}{|c|}{ Social behavior } \\
\hline & \multicolumn{2}{|c|}{ Aggression } & \multicolumn{2}{|c|}{ Withdrawal } & \multicolumn{2}{|c|}{ Prosocial } \\
\hline & Primary sample & $\begin{array}{c}\text { Cross-validation } \\
\text { sample }\end{array}$ & Primary sample & $\begin{array}{c}\text { Cross-validation } \\
\text { sample }\end{array}$ & Primary sample & $\begin{array}{c}\text { Cross-validation } \\
\text { sample }\end{array}$ \\
\hline \multicolumn{7}{|l|}{ Goal scale (ipsatized ${ }^{\mathrm{a}}$ ) } \\
\hline$+\mathrm{A}$ & .03 & .03 & -.06 & -.06 & -.02 & -.05 \\
\hline$+\mathrm{A}+\mathrm{C}$ & .01 & .08 & $-.19 * *$ & $-.15 * *$ & .09 & .10 \\
\hline$+\mathrm{C}$ & -.02 & -.10 & -.05 & .03 & $.28 * * *$ & $.32 * * *$ \\
\hline$-\mathrm{A}+\mathrm{C}$ & -.07 & -.04 & -.01 & -.07 & $.19 * *$ & $.12 *$ \\
\hline$-\mathrm{A}$ & $-.16 * *$ & -.07 & .10 & .05 & $.20 * *$ & $.16^{*}$ \\
\hline$-\mathrm{A}-\mathrm{C}$ & -.01 & $-.13 *$ & $.21 * * *$ & $.14 *$ & $-.16^{*}$ & .05 \\
\hline$-\mathrm{C}$ & .02 & .04 & .03 & .08 & $-.26 * * *$ & $-.28 * * *$ \\
\hline$+\mathrm{A}-\mathrm{C}$ & $.15^{*}$ & $.14^{*}$ & -.04 & -.05 & $-.21 * *$ & $-.30 * * *$ \\
\hline \multicolumn{7}{|l|}{ Vector score } \\
\hline Agentic goals & $.15^{*}$ & $.15^{*}$ & $-.19 * *$ & $-.14 *$ & -.08 & $-.17 * *$ \\
\hline Communal goals & -.05 & -.04 & $-.14 *$ & -.08 & $.33 * * *$ & $.32 * * *$ \\
\hline
\end{tabular}

Note. $\quad N=586$. IGI-C $=$ Interpersonal Goals Inventory for Children; Interpersonal Goal scales: $+\mathrm{A}+\mathrm{C}=\mathrm{Agentic}$ and Communal $+\mathrm{C}=\mathrm{Communal} ;$ $-\mathrm{A}+\mathrm{C}=$ Submissive and Communal $-\mathrm{A}=$ Submissive; $-\mathrm{A}-\mathrm{C}=$ Submissive and Separate; $-\mathrm{C}=\mathrm{Separate}$; $+\mathrm{A}-\mathrm{C}=\mathrm{Agentic}$ and Separate

${ }^{\text {a }}$ Scores expressed as deviations from their mean score across all the scales.

$* p<.05$. ** $p<.01$. *** $p<.001$.

more communal goals than boys. In addition, girls scored higher than boys on prosocial and withdrawal behaviors, whereas boys were more aggressive than girls.

To determine whether there were any direct relations between goals and social status (i.e., whether all paths were in fact mediated by social behaviors), a model including both direct and indirect paths between goals and social status was tested. In this model, none of the direct paths from goals to status was significant. Associations between goals and social status were therefore fully mediated by social behaviors.

\section{Social Goal Patterns Over Time}

Concurrently, children in Grades 5 and 6 pursued similar levels of agentic and communal goals. However, we wanted to investi- gate whether children displayed increased levels of agentic and communal goals over time (Time 1 and Time 2, 1 year apart) using a mixed model analysis of variance (ANOVA). The child's gender, initial grade level (Grade 5 or 6), and a dichotomous variable indicating the sample cohort $(1=$ primary sample, $2=$ crossvalidation sample) were used as the between-subjects factors and the Time 1 and Time 2 agentic and communal vector scores as the within-subjects factors. The results indicated that at Time 2 (in Grades 6 and 7), children reported increased levels of agentic goals, $F(1,413)=151.66, \eta^{2}=.27, p<.001$, as well as communal goals, $F(1,413)=33.78, \eta^{2}=.08, p<.001$, as compared with the levels they had reported at Time 1.

However, interaction effects between goals and gender, $F(1$, $413)=14.90, \eta^{2}=.04, p<.001$, for agentic goals, $F(1,413)=$

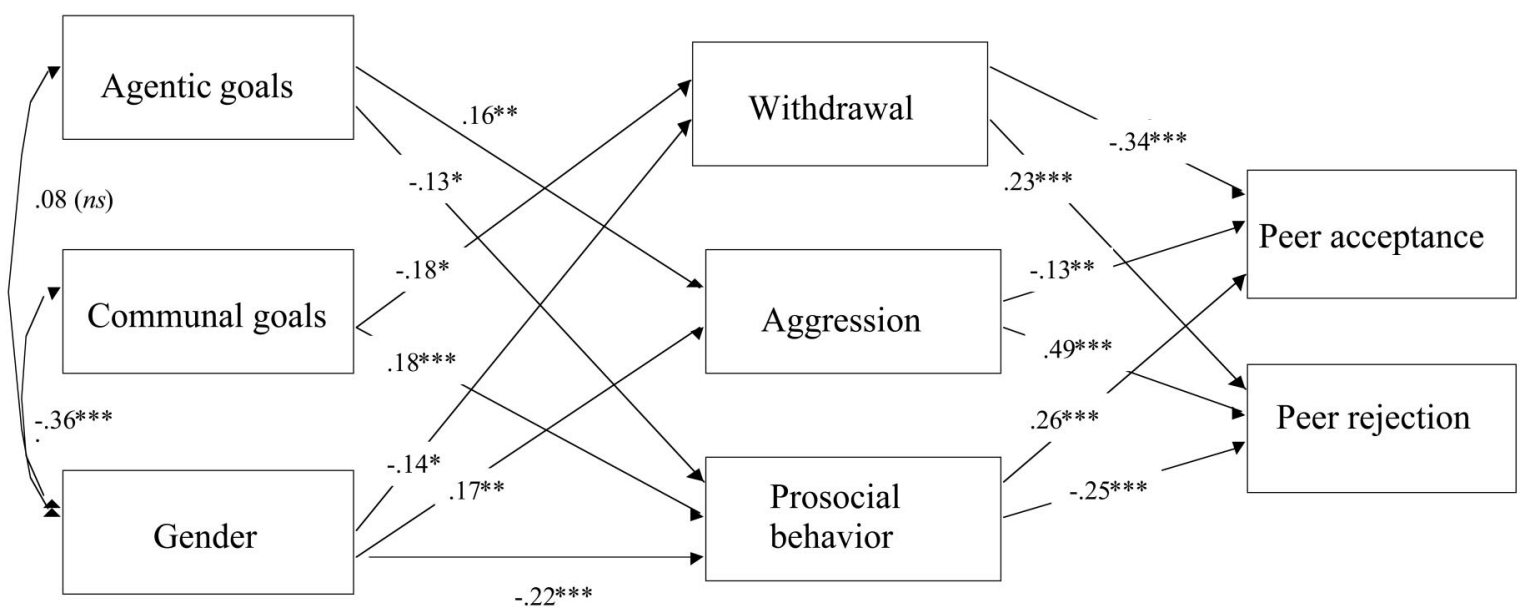

Figure 3. Path model of agentic and communal goals (vector scores), social behavior, and sociometric status $* p<.05 . * * p<.01 . * * * p<.001$. 
4.39, $\eta^{2}=.01, p<.05$; for communal goals, as well as a three-way interaction between communal goals, the grade level, and the sample cohort, $F(1,413)=4.28, \eta^{2}=.01, p<.001$, suggested that the increases in goals over time differed between boys and girls as well as between participants initially in Grades 5 and 6 and that the effect of the initial grade level depended on the sample cohort.

To investigate these patterns further, another mixed model ANOVA, including the initial grade level as a between-subjects factor and the Time 1 and Time 2 agentic and communal vector scores as within-subjects factors, was conducted separately for boys and girls in the two samples (i.e., four analyses altogether). Increases in the overall level of goals between Time 1 and Time 2 were found among both genders and in both samples. Results for the primary sample indicated that agentic goals increased for girls, $F(1,90)=62.32, \eta^{2}=.41 p<.001$, as well as for boys, $F(1$, $108)=14.12, \eta^{2}=.12, p<.001$; and that communal goals increased for boys, $F(1,108)=18.77, \eta^{2}=.15, p<.001$. The results for the cross-validation sample were similar. Agentic goals increased for girls, $F(1,101)=68.21, \eta^{2}=.40, p<.001$, as well as for boys, $F(1,114)=23.19, \eta^{2}=.17, p<.001$; whereas communal goals increased only for boys, $F(1,114)=15.39, \eta^{2}=$ $.12 p<.001$. The estimates of the effect sizes $\left(\eta^{2}\right)$ indicated that the increases in agentic goals were systematically larger than the increases in communal goals over time for both genders and in both samples.

\section{Discussion}

The main aim of the present study was to develop an inventory for children's social goals by applying the interpersonal circumplex model, adopted from adults (e.g., Gurtman, 1992; Kiesler, 1983), and to assess the psychometric properties of the new instrument. The fit of the circumplex model to children's social goals was tested twice in the first sample, with data collected 2 weeks apart and cross-replicated in another sample. The interpersonal goals of 11- to 13-year-olds conformed to a circumplex structure similar to that of adults' interpersonal goals and values (Dryer \& Horowitz, 1997; Locke, 2000). Moreover, the scales were reliable regarding internal consistency and across a 2 -week period. The present study can thus be regarded as an initial step taken in the direction of theoretically sound and psychometrically evaluated measurement of interpersonal goals in preadolescence.

Prior research has assessed different goal categories in different studies (e.g., Chung \& Asher, 1996; Renshaw \& Asher, 1993; Rose \& Asher, 1999), which has resulted in valuable but somewhat fragmented information on the ways in which social goals are related to children's social adjustment. The present findings add to this picture by presenting a comprehensive yet parsimonious assessment model, subsuming many of the previous goal concepts and by demonstrating the effectiveness of agentic and communal goal dimensions when predicting differences in children's social behaviors and social status with peers. However, it should be noted that the circumplex model may not equally adequately capture all variables previously conceptualized as social goals. Although social dominance may be described by the combination of agentic and separate goals (i.e., the aim for self-assertion without caring about the relationship with others), revenge goals (i.e., "getting back" with another; see, e.g., Rose \& Asher, 1999), for instance, encompass reactions to perceived hostility rather than domination and thus cannot be directly assessed in terms of agency and communality.

The assessment of a full range of interpersonal goals enabled us to examine the general structure of children's social goals as well as to investigate the development in goal dispositions over time. Given that children assigned more importance to communal than to agentic goals, our findings supported the predominant role of the striving for belongingness (see Baumeister \& Leary, 1995; Waldinger et al., 2002) in preadolescence. In agreement with accounts of gender role development (Maccoby, 1990), and with prior findings on children's social goals (Chung \& Asher, 1996; Jarvinen \& Nicholls, 1996; Rose \& Asher, 1999), boys pursued more agentic goals than girls, who instead endorsed more communal goals than boys. Given that children's social goals have been typically assessed in cross-sectional settings (e.g., Chung \& Asher, 1996; Rose \& Asher, in press), development of goals over time has been little understood. Our findings indicate that 11- to 13-year-olds pursue increased levels of agentic and communal goals over time, suggesting that the striving for status and intimacy with peers becomes more intense when approaching adolescence (see Buhrmester, 1990; Pellegrini \& Long, 2002). Given that agentic goals increased more than communal goals over time, our findings also suggest that the predominance of communal concerns becomes more balanced by agentic aims at the onset of adolescence.

A few cultural issues should be addressed. In Finland, the transition from Grade 6 to Grade 7 denotes the shift from lower to upper elementary school, which is typically considered a hallmark for entry into the "adolescent world." During this transition, children also disperse to various schools and classrooms. Prior studies report increases in domination and aggression during the transition from primary to secondary school, during which time aggression is used as a means to establish status with new peers (Pellegrini \& Long, 2002). Studies in which developmental shifts in goals in other cultures are investigated may show different findings, depending on what particular grade levels are considered as the transition into adolescence and whether children transfer to new classrooms (i.e., into unfamiliar peer groups) during the assessment period. In addition, future studies are needed to examine the extent to which interpersonal variables conform to the circumplex structure in other than the Western culture, where assertive individualism and mutual help coexist as principle values (see Sagara \& Pickett, 1998, for a review), thus reflecting relevant social motives. Whether interpersonal dispositions may be conceptualized around these dimensions in, for instance, Eastern cultures, where the conformity and intense interrelatedness denote groupbased rather than individually oriented motives (Sagara \& Pickett, 1998), needs to be evaluated in the future.

The present findings contribute to a broader life span perspective on social goals by showing that social goals may be conceptualized along the dimensions of agency and communality in preadolescence, as in adults. The adoption of an adult measure to children permits longitudinal investigations of whether goal orientations are stable across developmental transitions, where and when these goal orientations originate, and what key variables influence the emergence of stable patterns in social goals (i.e., temperament, working models of self and others) or account for changes in goal orientations as a result of intervention efforts. The existence of analogous measures for both children (IGI-C) and adults (CSIV; Locke, 2000; see also IGI; Dryer \& Horowitz, 1997) 
also provides the possibility to detect and intervene in maladaptive patterns of interpersonal adjustment earlier in life. For instance, adults with a fearful attachment style report interpersonal problems in the passive regions of the circumplex space (the lower quadrants), whereas adults with a dismissing attachment style experience problems related to a lack of warmth in social interaction (i.e., social separation in the circumplex space; see Bartholomew \& Horowitz, 1991). Depressed individuals, in turn, tend to manifest self-derogations judged by others as submissive, which implicate neither clear hostility nor friendliness (like or dislike) and thus eventually invite dominating reactions from others (Horowitz, Locke, Morse, \& Waikar, 1991).

Despite the fact that the circumplex model has been extensively studied and used to describe interpersonal phenomena for decades (e.g., Foa, 1961; Kiesler, 1983; see also Dryer \& Horowitz, 1997), the circular ordering of the assessed constructs has often been investigated with the "eye ball" test (i.e., plotting the items in the two-dimensional space and retaining the best representatives of each octant for the final measure), rather than using circumplex criteria of known effectiveness (Acton \& Revelle, 2002). Despite its limitations, the present study benefits from the fact that the circumplex structure of children's goals was investigated with the analysis developed specifically for this purpose.

The viewpoint of social motivation has been raised particularly in relation to aggressive behavior (see Erdley, 1996, for a review), and research on goals and behavior has most often investigated links between goals and aggressive behavior (e.g., Crick \& Dodge, 1996; Dodge, 1980; Dodge, Laird, Lochman, \& Zelli, 2002; Lochman et al., 1993). However, we observed even stronger associations between goals and prosocial behavior. It should be noted, however, that our prosocial items focused largely around affiliative tendencies. Given that prosocial behaviors include different dimensions reflecting, for instance, cooperation, comfort, or initiating and maintaining relationships (Greener \& Crick, 1999; Jackson $\&$ Tisak, 2001), connections between agentic and communal goals, and the distinct aspects of prosocial behaviors, should be evaluated in the future. The effects of goals on aggression and withdrawal were moderate. However, given that social behaviors are influenced by a range of different cognitions (Crick \& Dodge, 1994), aggressiveness especially by attributional biases (e.g., Graham \& Hudley, 1994), effects of this size may be considered to provide evidence of the independent influence of children's agentic and communal goals on their behaviors.

Our findings supported the hypothesis that social behaviors mediate the relation between social goals and sociometric status (Erdley \& Asher, 1996): Children's goals predicted their observed behaviors, which influenced their peers' perceptions of them. However, the analyses were based on concurrent data and thus preclude any conclusions about causality. The relations between goals, behavior, and social status are likely to be reciprocal rather than unidirectional. Recent evidence points in the direction of cognitive-behavioral cycles (e.g., Safran, 1990), in which social cognition leads to interpersonal events (e.g., gaining acceptance from peers) that confirm or support the cognitive structures. For instance, changes in peer acceptance and rejection have been shown to precede changes in aggression and prosocial behavior (Haselager, Cillessen, Van Lieshout, Riksen-Walraven, \& Hartup, 2002). Only longitudinal studies can uncover the influence of peer acceptance or rejection on subsequent goal endorsement and social behavior (e.g., children may alter their goal endorsement and/or behavior according to their acceptance level in the peer group).

Inventories have been criticized for the fact that the recognition of the adaptive goals may not differentiate between groups (e.g., aggressive or nonaggressive) as well as the goal construction process assessed with the open-ended interviews (Crick \& Dodge, 1994; Renshaw \& Asher, 1983). However, the inventory approach enabled us to detect meaningful connections between goals and social behavior as well as social status. Together with other recent work (e.g., Lemerise et al., 2003; Rose \& Asher, 1999; Underwood \& Bjornstad, 2001), our findings thus indicate that inventories with subjective importance ratings of goals possess adequate discriminant validity. Of course, the methods used in child assessment depend on the age of the participants: Inventories can be used effectively for elementary through middle-school samples and onward, whereas the widely used interview methods are justified for use with younger children. However, the present theoretical framework is not limited to the questionnaire method but can be used as a conceptual basis for children's goal assessment in various research settings, such as coding open-ended interviews or even with observational data.

The replication of the fit of the circumplex model, and the goal-behavior links, across the two samples can be considered as strengths of the study. We were also able to avoid the problems of shared method bias when examining the links between selfreported goals and peer-reported behaviors. However, because the nominations for social behavior and sociometric status were retrieved from the same children (classmates), possible source effects may have resulted in inflated links between social behaviors and sociometric status. A limitation concerning the absence of the individual SES levels should also be noted. Although the differences in students' SES between or within Finnish elementary schools are not that large, future studies would benefit from examining whether SES levels influence childrens' pursuit of agentic and communal goals with peers. Furthermore, we investigated goals separately from other indexes of social information processing. Self-efficacy beliefs (e.g., Bandura \& Locke, 2003), for instance, influence goal endorsement, as children tend to select the goals that they feel able to achieve (Erdley \& Asher, 1996), and feelings of self-efficacy may also moderate the associations between goals and behavior. How agentic and communal goals operate in concert with other social cognitions needs to be investigated. Finally, given that children are assumed to change their goals in response to situational cues (Crick \& Dodge, 1994), future studies are needed to examine childrens' agentic and communal goals in different social situations. In fact, the IGI-C appears to yield valid data also when goals are assessed across specific situational contexts (Ojanen, Aunola, \& Salmivalli, 2004).

\section{References}

Acton, G., \& Revelle, W. (2002). Interpersonal personality measures show circumplex structure based on new psychometric criteria. Journal of Personality Assessment, 79, 456-481.

Asher, S. (2004, July). Commentary on "Social goals: A motivational approach to children's social adjustment," a symposium (E. Lemerise \& C. Salmivalli, Chairs) conducted at the biennial meeting of the International Society for the Study in Behavioral Development, Ghent, Belgium. 
Austin, J., \& Vancouver, J. (1996). Goal constructs in psychology: Structure, process, and content. Psychological Bulletin, 120, 338-375.

Bandura, A., \& Locke, E. (2003). Negative self-efficacy and goal effects revisited. Journal of Applied Psychology, 88, 87-99.

Bartholomew, K., \& Horowitz, L. (1991). Attachment styles among young adults: A test of a four-category model. Journal of Personality and Social Psychology, 61, 226-244.

Baumeister, R., \& Leary, M. (1995). The need to belong: Desire for interpersonal attachments as a fundamental human motivation. Psychological Bulletin, 117, 497-529.

Buhrmester, D. (1990). Intimacy of friendship, interpersonal competence, and adjustment during preadolescence and adolescence. Child Development, 61, 1101-1111.

Buhrmester, D. (1996). Need fulfillment, interpersonal competence, and the developmental contexts of early adolescent friendship. In W. Bukowski, A. Newcomb, \& W. Hartup (Eds.), The company they keep: Friendship in childhood and adolescence (pp. 158-185). New York: Cambridge University Press.

Chung, T., \& Asher, S. (1996). Children's goals and strategies in peer conflict situations. Merrill-Palmer Quarterly, 42, 125-147.

Crick, N., \& Dodge, K. (1994). A review and reformulation of social information-processing mechanisms in children's social adjustment. Psychological Bulletin, 115, 74-101.

Crick, N., \& Dodge, K. (1996). Social information-processing mechanisms in reactive and proactive aggression. Child Development, 67, 993-1002.

Dodge, K. (1980). Social cognition and children's aggressive behavior. Child Development, 51, 162-170.

Dodge, K., Asher, S., \& Parkhurst, J. (1989). Social life as a goal coordinating task. In C. Ames \& R. Ames (Eds.), Research on motivation in education (pp. 107-135). San Diego, CA: Academic Press.

Dodge, K. A., Laird, R., Lochman, J. E., \& Zelli, A. (2002). Multidimensional latent-construct analysis of children's social information processing patterns: Correlations with aggressive behavior problems. Psychological Assessment, 14, 60-73.

Dryer, D., \& Horowitz, L. (1997). When do opposites attract? Interpersonal complementarity versus similarity. Journal of Personality and Social Psychology, 72, 592-603.

Erdley, C. (1996). Motivational approaches to aggression within the context of peer relationships. In J. Juvonen \& K. Wentzel (Eds.), Social motivation: Understanding children's school adjustment. Cambridge studies in social and emotional development (pp. 98-125). New York: Cambridge University Press

Erdley, C., \& Asher, S. (1996). Children's social goals and self-efficacy perceptions as influences on their responses to ambiguous provocation. Child Development, 67, 1139-1344.

Fitzsimons, G., \& Bargh, J. (2003). Thinking of you: Nonconscious pursuit of interpersonal goals associated with relationship partners. Journal of Personality and Social Psychology, 84, 148-164

Foa, U. (1961). Convergences in the analysis of the structure of interpersonal behavior. Psychological Review, 68, 341-355.

Graham, S., \& Hudley, C. (1994). Attributions of aggressive and nonaggressive African-American male early adolescents: A study of construct accessibility. Developmental Psychology, 30, 365-373.

Greener, S., \& Crick, N. (1999). Normative beliefs about prosocial behavior in middle childhood: What does it mean to be nice? Social Development, 8, 349-363.

Gurtman, M. (1992). Construct validity of interpersonal personality measures: The interpersonal circumplex as a nomological net. Journal of Personality and Social Psychology, 63, 105-118.

Haselager, G., Cillessen, A., Van Lieshout, C., Riksen-Walraven, M., \& Hartup, W. (2002). Heterogeneity among peer-rejected boys across middle childhood: Developmental pathways of social behavior. Developmental Psychology, 38, 446-456.

Hawley, P. (2002). Social dominance and prosocial and coercive strategies of resource control in preschoolers. International Journal of Behavioral Development, 26, 167-176.

Hawley, P. (2003). Strategies of control, aggression, and morality in preschoolers: An evolutionary perspective. Journal of Experimental Child Psychology, 85, 213-235.

Hawley, P., Little, T., \& Pasupathi, M. (2002). Winning friends and influencing peers: Strategies of peer influence in late childhood. International Journal of Behavioral Development, 26, 466-474

Horowitz, L., Locke, K., Morse, M., \& Waikar, S. (1991). Self-derogations and the interpersonal theory. Journal of Personality and Social Psychology, 61, 68-79.

Hubert, L., \& Arabie, P. (1987). Evaluating order hypothesis within proximity matrices. Psychological Review, 90, 185-214.

Jackson, M., \& Tisak, M. (2001). Is prosocial behavior a good thing? Developmental changes in children's evaluations of helping, sharing, cooperating, and comforting. British Journal of Developmental Psychology, 19, 349-367.

Jarvinen, D., \& Nicholls, J. (1996). Adolescents' social goals, beliefs about the causes of social success, and satisfaction in peer relations. Developmental Psychology, 32, 435-441.

Kiesler, D. (1983). The 1982 interpersonal circle: A taxonomy for complementarity in human transactions. Psychological Review, 90, 185-214.

Lemerise, E., Trame, B., \& Crafton, K. (2003, April). Fitting emotion into a social information processing model of social competence. Paper presented at the biennial meeting of the Society of Research on Child Development, Tampa, FL.

Lochman, J., Wayland, K., \& White, K. (1993). Social goals: Relationship to adolescent adjustment and to social problem solving. Journal of Abnormal Child Psychology, 21, 135-151.

Locke, K. (2000). Circumplex scales of interpersonal values: Reliability, validity, and applicability to interpersonal problems and personality disorders. Journal of Personality Assessment, 75, 249-267.

Locke, K. (2003). Status and solidarity in social comparison: Agentic and communal values and vertical and horizontal directions. Journal of Personality and Social Psychology, 84, 619-631.

Luthar, S., \& McMahon, T. (1996). Peer reputation among inner-city adolescents: Structure and correlates. Journal of Research on Adolescence, 6, 581-603.

Maccoby, E. (1990). Gender and relationships: A developmental account American Psychologist, 45, 513-520.

Múthen, L., \& Múthen, B. (1998-2001). Mplus: Statistical analysis with latent variables. User's guide. Los Angeles: Author.

Ojanen, T., Aunola, K., \& Salmivalli, C. (2004, July). Changing goals according to changing situations? Connections between children's situation-specific goals and their social adjustment. Paper presented at the biennial meeting of the International Society for Behavioral Development, Ghent, Belgium.

Pellegrini, A., \& Long, J. (2002). A longitudinal study of bullying, dominance, and victimization during the transition from primary school through secondary school. British Journal of Developmental Psychology, 20, 259-280.

Renshaw, P., \& Asher, S. (1983). Children's goals and strategies for social interaction. Merrill-Palmer Quarterly, 29, 353-374.

Rodkin, P., \& Farmer, T. (2000). Heterogeneity of popular boys: Antisocial and prosocial configurations. Developmental Psychology, 36, 14-24.

Rose, A., \& Asher, S. (1999). Children's goals and strategies in response to conflicts within a friendship. Developmental Psychology, 35, 69-79.

Rose, A., \& Asher, S. (in press). Children's strategies and goals in response to help-giving and help-seeking tasks within a friendship. Child Development.

Safran, J. (1990). Towards a refinement of cognitive therapy in light of interpersonal theory: I. Theory. Clinical Psychology Review, 10, 87-105.

Sagara, M., \& Pickett, M. (1998). Sociocultural influences and care of dying children in Japan and the United States. Cancer Nursing, 21, 274-281.

Sutton, J., Smith, P., \& Swettenham, J. (1999). Bullying and "theory of 
mind": A critique of the "social skills deficit" view of anti-social behavior. Social Development, 8, 117-127.

Tracey, T. (1997). RANDALL: A Microsoft FORTRAN program for a randomization test of hypothesized order relations. Educational and Psychological Measurement, 57, 164-168.

Underwood, M., \& Bjornstad, G. (2001). Children's emotional experience of peer provocation: The relation between observed behaviour and self-reports of emotions, expressions, and social goals. International Journal of Behavioral Development, 25, 320-330.

Waldinger, J., Diguer, L., Guastella, F., Lefebvre, R., Allen, J., Luborsky,
L., \& Hauser, S. (2002). The same old song?-Stability and change in relationship schemas from adolescence to young adulthood. Journal of Youth and Adolescence, 31, 17-29.

Wentzel, K., \& Erdley, C. (1993). Strategies for making friends: Relations to social behavior and peer acceptance in early adolescence. Developmental Psychology, 29, 819-826.

Wiggins, J., Phillips, N., \& Trapnell, P. (1989). Circular reasoning about interpersonal behavior: Evidence concerning some untested assumptions underlying diagnostic classification. Journal of Personality and Social Psychology, 59, 296-305.

\section{Appendix}

\section{Scale Items of the Interpersonal Goal Inventory for Children (IGI-C).}

\section{Agentic Goals $(+A)$}

1. The others respect and admire you.

2. You appear self-confident and make an impression on the others.

3. The others think you are smart.

Agentic and Communal Goals $(+A+C)$

1. You say exactly what you want.

2. The others listen to your opinion.

3. You state your opinion plainly.

4. You are able to tell the others how you feel.

Communal Goals $(+C)$

1. You feel close to the others.

2. Everyone feels good

3. You can put the others in a good mood

4. Real friendship develops between you.

Submissive and Communal Goals $(-A+C)$

1. Your peers like you.

2. The others accept you.

3. You are invited to join in games.

4. You agree with the others about things.

5. You let the others decide.

Submissive Goals (-A)

1. The others do not get angry with you.

2. You do not make the others angry.
3. You are able to please the others.

4. You do not annoy the others.

Submissive and Separate Goals $(-A-C)$

1. You do not do anything ridiculous.

2. You do not say stupid things when the others are listening

3. Your peers do not laugh at you.

4. You do not make a fool of yourself in front of the others.

Separate Goals $(-C)$

1. You do not show your feelings in front of your peers.

2. You do not give away too much about yourself

3. You keep your thoughts to yourself.

4. You keep the others at a suitable distance.

5. You do not let anyone get too close to you.

6. You do not show that you care about them.

Agentic and Separate Goals $(+A-C)$

1. The others agree to do what you suggest.

2. You get to decide what to play.

3. The group does what you say.
Received January 26, 2004 Revision received December 3, 2004 Accepted December 23, 2004 